\title{
FEDEA
}

\section{Housing deprivation and health status: \\ Evidence from Spain}

by

Luis Ayala*

José M. Labeaga**

Carolina Navarro***

DOCUMENTO DE TRABAJO 2005-02

Febrero 2005

* Universidad Rey Juan Carlos, Madrid.

** UNED, FEDEA, Madrid.

*** UNED, Madrid.

Los Documentos de trabajo se distribuyen gratuitamente a las Universidades e Instituciones de Investigación que lo solicitan. No obstante están

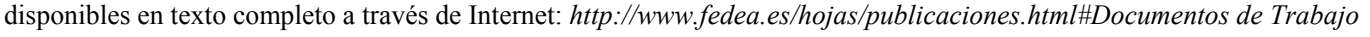

These Working Documents are distributed free of charge to University Department and other Research Centres. They are also available through Internet: http://www.fedea.es/hojas/publicaciones.html\#Documentos de Trabajo 
Depósito Legal: M-2957-2005 


\begin{abstract}
Living in inadequate housing conditions not only supposes a failure of a basic functioning. It also has effects on other essential aspects of well-being such as health. Very few studies to date have analysed the relationship between both questions making an attempt to assess whether observable or unobservable individual characteristics can condition this relationship. This study questions to what extent living in poor housing conditions can determine individuals' health status once the possible influence of other factors is controlled for. By estimating a logistic model with individual effects and building-up a housing deprivation index based on a latent variable model, we reach a number of relevant conclusions concerning the mentioned relationship. There is a negative effect of this kind of deprivation on the individuals' health, both when housing conditions are analysed in a disaggregated manner and when they are combined in a latent variable context. The importance of controlling both observable and unobservable heterogeneity among individuals also stands out. The need for co-ordinating the health care policy with other policies such as the housing one, in order to promote better levels of health can also be inferred from the results.
\end{abstract}

JEL: I10, I30.

Key words: housing deprivation, unobserved heterogeneity, latent class models.

\title{
Resumen
}

La vida en viviendas que no reúnen condiciones adecuadas supone, al margen de un fallo de funcionamiento básico en la sociedad, un germen para la aparición de otros problemas relacionados con el bienestar de los individuos, con efectos potenciales sobre su salud, por ejemplo. No es común en la literatura el estudio de estas relaciones en contextos en los que no sólo se tengan en cuentan variables observadas (características de la vivienda y de los individuos) sino variables no observadas, como características genéticas, que pueden tener influencia sobre la salud, erróneamente atribuida a otros factores. En este trabajo tratamos de estudiar las relaciones causales entre las condiciones de la vivienda y el estado de salud de los individuos. En el contexto de modelos de elección discreta con datos de panel tomados del Panel de Hogares de la Unión Europea, explicamos el estado de salud en dos contextos: i) utilizando directamente las variables que recogen las características de la vivienda, tal como las proporciona la encuesta; ii) construyendo un índice de privación, mediante un modelo de clase latente e incluyendo este índice como aproximación al estado de la vivienda en la ecuación de estado de salud. En ambos contextos, la evidencia de que las malas condiciones en las que los individuos viven afectan negativamente su estado de salud es muy robusta. Además, ponemos de manifiesto la importancia de incluir factores no observables en la especificación. De los resultados que obtenemos se infiere la necesidad de poner en práctica políticas coordinadas de salud y vivienda si se pretenden conseguir mejoras en el nivel de bienestar de individuos especialmente desfavorecidos.

JEL: I10, I30.

Key words: privación de vivienda, heterogeneidad no observada, modelos de clase latente. 


\section{INTRODUCTION*}

In recent years, there has been a significant increase in the number of studies that make an attempt to estimate the influence of various factors on individuals' health status. These include demographic, hereditary, lifestyle, as well as various socio-economic factors. Among the relationships that have aroused interest, one of the most complex is the relationship between housing conditions and health. The publication of a growing number of studies has contributed to consolidate the evidence on the negative impact that living in poor housing conditions has on health status. This development has allowed analytical methods to be improved and applied to ever more complete databases. Some studies have taken a cross-sectional approach while others attempt to look into the effects exerted by housing deprivation on health from a longitudinal perspective.

A consensus has been reached on identifying the housing conditions that have a negative effect on the health status of individuals. These housing conditions include overcrowding (infectious and respiratory diseases), damp (respiratory problems, eczema and asthma), cold or low temperatures (heart diseases, bronchitis, hypothermia and respiratory diseases) and rot in floors or window frames (asthma). A report published by the British Medical Association Board of Science and Education points out that living in dwellings with leaky roofs, damp and overcrowded living conditions has a negative effect on the most vulnerable groups of society. The same study underlines that the greatest health risks are run by elderly people above the age of 65 living alone in old dwellings. It also highlights the lower levels of educational attainment achieved by children living in overcrowded housing conditions. When comparing to other health risk factors, the negative influence exerted by multiple housing deprivation is of a similar magnitude as smoking and greater than that exerted by excessive alcohol consumption. Some studies even establish a strict relationship between housing conditions and mortality rates.

However, interest in this relationship varies considerably among OECD countries. Most of the empirical studies deal with the United Kingdom. Different lines of research have been developed on the relationship between

\footnotetext{
${ }^{*}$ We thank the Inter-ministerial Commission on Science and Technology (SEC2001 0746 and BEC2002 04294C01) for the funding received. We are grateful to Rosa Urbanos of the University Complutense of Madrid and Irini Moustaki of London School of Economics and Political Science for her valuable and helpful comments as well as to seminar participants at Institute for Social and Economic Research (ISER) in the -University of Essex, Universidad Complutense, UNED, Encuentro de Economía Pública, Jornadas de Economía de la Salud and International Conference on Microeconometric Models and Simulation Tools for Fiscal Policy hold at the Spanish Institute for Fiscal Studies.
} 
health and housing since the pioneering work done at the end of the $19^{\text {th }}$ century, which came about as a result of a concern for and an interest in the consequences that poor housing conditions had on health in the Victorian era. There are four main areas of analysis: 1) studying the disadvantages of individuals suffering from health problems in the housing market; 2) analysing homeless people's access to health services; 3) assessing the pathological consequences of living in bad housing conditions; and 4) examining the stress associated with not being able to gain access to adequate housing and its possible effect on health (mental]. Research on these relationships received an additional impetus at the end of the 1990s when it was incorporated more visibly into the British government's political agenda.

The theoretical and empirical body of work developed in other countries coincides in revealing that guaranteeing adequate housing not only means covering a basic need but that it also produces external effects on other dimensions of well-being, like health. Thus policies geared toward favouring access to housing for the homeless can lead to lower national health system costs, for instance. Evidence for Canada shows that the cost of social and health care services for the homeless is 30 per cent higher than the costs that would arise if the homeless were re-housed and maintained in specially designed dwellings.

The aim of this study is to analyse the influence that living in a dwelling suffering from certain deficiencies - such as a lack of certain facilities, overcrowding or other structural problems - has on the health status of individuals. We use an analytical model that incorporates some novelties when compared to previous studies. More specifically, probability decision models are used, which are adjusted using the Spanish waves of the European Community Household Panel (ECHP) from 1995 to 1998. The importance of introducing unobservable heterogeneity into the decision models that endeavour to establish an empirical relationship between housing deprivation and individuals' health status is taken into account. Controlling heterogeneity enables certain factors such as the pre-existing stock of health to be identified as fixed effects. A second novelty resides in the way housing deprivation is represented. The twofold fact that the different housing conditions may be endogenous in a model that tries to explain the individuals' health status and the need to prove the validity of these factors as health proxies, both individually and as a group, have led us to construct a latent variable that summarises such characteristics.

The structure of the study is as follows. The theoretical grounds of the relationship to be studied are reviewed in the following section. The 
econometric specifications are presented in the third section. The possibilities and constraints of the data used for the empirical work as well as the results are presented and interpreted in the fourth section. The study ends up with a brief list of conclusions.

\section{THEORETICAL FRAMEWORK}

The wide variety of elements that come into play when assessing the effects of housing deprivation on health makes it necessary to develop a general analytical model capable of exploring this kind of questions. The key to this model lies in identifying a function of health production. Until the first studies analysing the possible effects of a vector of factors on health within the framework of a production function, most of the empirical works focused on analysing the effects of health services. Auster et. al (1969) was one of the first studies that introduced an overall function of health production in which the effects of other factors were added to the health services.

The model developed by Grossman, which analyses how individuals allocate their resources to produce health, is the most relevant theoretical framework to explain an individual's health status. In this model, health represents a durable capital stock which output is healthy time. Each individual owns an initial amount of such stock that depreciates with age and can be increased with investment. The demand for health consist of two elements: consumption commodity (which enters directly in the utility function) and investment commodity (which determines the total amount of time available for market and non-market activities).

This theoretical framework has had a great influence on numerous studies, both theoretical and empirical. Rosenzweig and Schultz differentiated two kinds of factors in the health production function. The first set of factors includes choices made by the individual, while the other set consist of exogenous elements that can be considered as given in the function of health production. This distinction between exogenous and endogenous factors was introduced by Becker. Many of the studies after Rosenzweig and Schultz reflect this differentiation. Kenkel used the health production function framework to analyse the importance of lifestyles on health. The former are determined by the choices made by individuals. The stock of health $H$ is produced as a function of the production technology given by: 


$$
H=H(L, S, X)
$$

were $L$ represents the various lifestyles (eating breakfast regularly, proper weight, number of sleeping hours, consumption of tobacco and alcohol, sport, among others), $S$ represents the stock of human capital and $X$ includes different variables (age, sex, ethnic origin, chronic diseases, among others) that can have an influence on the productivity of gross investment, the stock of pre-existing health or the determining factors of the rate of depreciation. The inclusion of these factors responds to the fact that health is considered an essential commodity including aspects of both consumption and capital.

A possible alternative to examine the importance of housing conditions on individuals' health is to adapt this function by incorporating variables that reflect housing characteristics (lack of certain facilities, structural problems or overcrowding). The main difficulty involved in transforming the Kenkel model to empirical analyses lies in the fact that introducing variables that refer to the behaviour of individuals makes the specification of the function very complex. The need for information about lifestyles comes up against the common shortage of data on individual habits. A variation could lie in the introduction of an alternative assumption: the rest of the regressors included in the model would provide information on the individuals' lifestyles. This vector of regressors includes different variables that measure the stock of health (age), rate of depreciation, pre-existing health (chronic diseases), gross investment (educational attainment), housing deprivation (lack of certain facilities, structural problems, overcrowding) and other variables having an incidence on the investment's productivity. As Contoyannis and Jones pointed out, the latter should include information about the household member's characteristics (marital status), social class (level of income) or labour market conditions (employment status).

The model incorporating housing conditions $(V)$ could be formulated as follows:

$$
H=H(L, V, S, D)
$$

where all the variables have been previously defined and we assume that $L$ is represented by: 


$$
L=(V, S, X)
$$

This specification implies that the results that can be obtained should be interpreted by taking into account that the marginal effects derived from it not only gather information about the influence of the set of regressors on the health status but also include the changes caused by lifestyles.

Even in the case in which observed heterogeneity are controlled by a wide set of determining factors is possible, as we pointed out above, that unobserved effects of individuals (genetic characteristics) could directly affect on health status or indirectly by not included factors in lifestyles (tastes). Thus the objective of this second approach is to adequate the empirical specification to the existing panel data in order to carry out the analysis.

\section{ECONOMETRIC SPECIFICATION AND METHODOLOGY}

\subsection{Discrete choice panel data models}

Moving on to the empirical field from the theoretical framework set out above requires transforming the health production model into an empirical one including the different dimensions previously outlined. This model could be based on considering the effects that the different dimensions of housing deprivation have on the health status expressed as a binary variable, namely being in good or bad health. To do so, it would be necessary to ensure that each of the housing deprivation components is a suitable measurement of such latent dimension and constitutes a good proxy of the health status, both individually and as a group. For these reasons, we will include a disaggregated vector of household characteristics in a preliminary approximation to the relationship between housing and health. In a subsequent approximation, we will set out a model that sums up all the housing dimensions in a single variable representing deprivation in order to compare its relevance as a proxy for the health of individuals.

The simplest way to approach the relationship between the two variables mentioned above consists of estimating a binary logistic regression model. Although the reported health status is a multinomial variable in which the different characteristics have an order, for the sake of simplicity and following other authors we choose to transform the dependent variable into a dichotomic indicator. A way of constructing this variable is based on using each individual's own perceptions. The ECHP offers individual subjective assessments on health 
status that can be sorted hierarchically as follows: "very bad", "bad", "fair", "good" and "very good". Despite the fact that incorporating subjective variables can be open to criticism, there are arguments that back the notion of subjectivity as one of the main advantages provided by this kind of assessments. Some studies also reveal that there is a significant relationship between this variable and other health measures. We build a new variable summing up in two categories the information provided by the previous one: "being unhealthy", which refers to individuals that state they are in fair, bad or very bad health, and "being healthy", which includes the individuals that state they are in good or very good health. We have estimated ordered and binary logit models in order to test the equivalence of the categories that have finally been chosen.

Because data on the same individuals are available for various years, the binary choice model has to take into consideration both dimensions:

$$
H_{i t}^{*}=\beta^{\prime} Z_{i t}+\varepsilon_{i t}, \mathrm{i}=1, \ldots, \mathrm{n}, \quad \mathrm{t}=1, \ldots, \mathrm{T}
$$

where $Z=(L, V, S, X)$.

In order to provide an overall simplified version, we begin by adopting the assumptions of common idiosyncratic shocks and uncorrelated mixed errors. In other words, $\varepsilon_{i t}=\varepsilon_{i}+v_{i t}$, in which $\varepsilon_{i}=\varepsilon, \forall i$ with $v_{i t}$ serially uncorrelated. Despite the limitations that this approach entails, the purpose of this preliminary approximation is to obtain some naïve estimators in order to be able to compare them with results correspondinng to more complex model subsequently.

Some of the previous assumptions like the use of data on the same individuals for different time units are then reviewed in a second model and the results are compared. There are two related aims. First, we like to relax the hypothesis of homogeneity in the response of the individuals; second, we want to check whether unobserved individuals' lifestyles or their genetics are correlated with the observable explanatory factors included and to what extent their exclusion bias the results. In doing this we exploit the most important advantages of using panel instead of cross-section data. In terms of the specification, the structural logistic model can now be formulated as in equation (4), but we relax the assumption that $\varepsilon_{i}=\varepsilon, \forall i$ although maintaining that $v_{i t}$ are serially uncorrelated. The probability of being unhealthy when homogeneity is imposed is: 


$$
\operatorname{Pr}\left[H_{i t}=1\right]=\operatorname{Pr}\left[H_{i t}^{*}>0\right]=\operatorname{Pr}\left[\varepsilon_{i t}>-z_{i t}^{\prime} \beta\right]=F\left(z_{i t}^{\prime} \beta\right)
$$

where $F$ represents the cumulative function of the logistic distribution. When relaxing the assumption of homogeneity, this probability becomes:

$$
\operatorname{Pr}\left[H_{i t}=1\right]=\operatorname{Pr}\left[H_{i t}^{*}>0\right]=\operatorname{Pr}\left[v_{i t}>-\beta z_{i t}^{\prime}-\varepsilon_{i}\right]=F\left(z_{i t}^{\prime} \beta+\varepsilon_{i}\right)=\frac{e^{\varepsilon_{i}+\beta^{\prime} z_{i t}}}{1+e^{\varepsilon_{i}+\beta^{\prime} z_{i t}}} .
$$

Since in (5) we have a problem of nuisance parameters, our guess is that individual effects could be correlated to the rest of the regressors included in the model, so that we assume:

$$
E\left(z_{i t} \varepsilon_{i}\right) \neq 0
$$

In order to incorporate this possibility, we assume that $E\left(\varepsilon_{i} / z_{i t}\right)=\lambda \bar{z}_{i}$. It then follows that:

$$
H_{i t}^{*}=\beta z_{i t}+\lambda \bar{z}_{i}+\eta_{i}+v_{i t}
$$

where the individual effects are given by $\varepsilon_{i}=\lambda \bar{z}_{i}+\eta_{i}$ and we assume that $E\left(\eta_{i} z_{i}\right)=0$. We are aware of two restrictions incorporated in the specification of the effects, assuming a linear function for them as well as a lack of correlation of $\eta$ 's and $z$ 's. In any event, these two assumptions can be relaxed and tested.

Estimating the logistic model with individual effects enables us to confirm or refute, should it be the case, the results obtained by the model that does not take into consideration the panel structure of the data. In order to fulfill the two previously mentioned aims, it is necessary to conduct a prior comparison that would allow us to know whether or not unobserved heterogeneity actually exists. A likelihood ratio (LR) test compares the two specifications. In our case, we have under the null a homogenous model and we relax this assumption under the alternative hypothesis by allowing for the presence of individual heterogeneity. Thus, the LR can be written as: 


$$
-2 \operatorname{Ln} \lambda=-2 \operatorname{Ln}\left(\frac{\hat{L}_{R}}{\hat{L}_{U}}\right)
$$

where $\hat{L}_{R}$ and $\hat{L}_{U}$ are the values of the log-likelihood function at the optimum evaluated for the restricted and unrestricted models, respectively. It follows under the null a $\chi^{2}$ distribution with degrees of freedom equal to the number of restrictions imposed when moving from the unrestricted to the restricted specification.

Finally, it is also necessary to prove that the components or indicators making up the housing deprivation index serve as a proxy for the health of individuals. A latent variable representing housing deprivation in each period is constructed in order to summarise these different dimensions in a single variable that would allow us to test the results obtained from the previous model.

\subsection{Latent variable models to build a deprivation index}

Latent variable models, and more specifically latent trait models, offer a suitable methodological framework to solve problems like the aggregation of different basic dimensions. These models use multivariate analysis techniques to measure an unobserved concept like housing deprivation derived from a set of observed items. Essentially, the main objectives of latent variable models are to reduce the dimensionality of the set of observed variables and assign the values corresponding to latent variables to each individual as a function of the responses obtained for each of the observed variables. This is done either to analyse and identify the latent variables underlying a set of observed indicators, or to prove if a specific set of indicators measuring certain concrete concepts reveal a supposed a priori hypothetical structure. The partial indicators chosen will constitute the supposed a priori hypothetical structure that will be tested by means of the latent trait model. An alternative would consist of assessing the consistency of the deprivation indicators by estimating the Cronbach Alpha coefficient. Nevertheless, the use of such methods suffers from some important constraints.

The second advantage these models offer is that they allow us to synthesise a set of partial indicators of the same phenomenon into a single index. This is made taking into account the correlation among these components and their mutual dependence on the latent variable. These techniques are appropriate 
for the nature of the set of observed variables (dichotomous variables) and allow different additive weights to be assigned to them. The latent trait model is defined as follows:

$$
\operatorname{logit} \pi_{\mathrm{i}}(\mathrm{y})=\log \frac{\pi_{i}(y)}{1-\pi_{i}(y)}=\alpha_{\mathrm{i} 0}+\sum_{j=1}^{q} \alpha_{i j} y_{j}
$$

where

$$
\pi_{\mathrm{i}}(\mathrm{y})=\frac{\exp \left(\alpha_{i 0}+\sum_{j=1}^{q} \alpha_{i j} y_{j}\right)}{1+\exp \left(\alpha_{i}+\sum_{j=1}^{q} \alpha_{i j} y_{j}\right)}
$$

where in the unidimensional case we use instead of the sum, the expresion $\exp \left(\alpha_{i 0}+\alpha_{i} y\right)$.

In the latent trait model, each observed housing condition would correspond to $q+1$ parameters to be estimated $\left(\alpha_{i 0}\right.$ and the factor loadings $\alpha_{i 1}, \ldots$, $\left.\alpha_{\mathrm{iq}}\right)$. If $\mathrm{y}_{1}=\ldots=\mathrm{y}_{\mathrm{q}}=0, \pi_{\mathrm{i}}(0)=\left[\exp \left(\alpha_{\mathrm{i} 0}\right) /\left(1+\exp \left(\alpha_{\mathrm{i} 0}\right)\right)\right]$. $\alpha_{\mathrm{i} 0}$ represents the probability of a median individual suffering deprivation of the observed condition, while $\alpha_{\mathrm{ij}}$ are discrimination parameters. The higher the value of $\alpha_{\mathrm{ij}}$ is for an observed condition, the greater the difference in the probability of obtaining a positive response between two individuals situated at a certain distance apart on the latent dimension. The higher the parameter is, the easier will be to discriminate between two individuals on the basis of their level of deprivation concerning each observed condition.

The assumptions adopted by the latent trait model are conditional independence (the vector of latent variables account for all the associations among the responses given for the set of observed variables), the independent nature of the latent variables with standard normal distributions so that $y_{j} \sim \mathrm{N}$ $(0,1), j=1, \ldots, \mathrm{q}$, and that the link function can be either a logit or a probit function.

Given that only the observed variables $\mathrm{x}_{1}, \ldots, \mathrm{x}_{\mathrm{p}}$ can be known, the estimation of the unknown parameters is based on their joint distribution function: 


$$
f\left(x_{1}, \ldots, x_{p}\right)=\int \ldots \int g\left(x_{1}, \ldots, x_{p} \mid y\right) h(y) d y
$$

where we assume the conditions of conditional independence, a Bernoulli distribution for each $\mathrm{x}_{\mathrm{i}}$ and independent latent variables:

$$
\begin{aligned}
g\left(x_{1}, \ldots, x_{p} \mid y\right)=g\left(x_{1} \mid y\right) \ldots g\left(x_{p} \mid y\right) & =\prod_{i=1}^{p} g\left(x_{i} \mid y\right), g\left(x_{i} \mid y\right)=\left\{\pi_{i}(y)\right\}^{x_{i}}\left\{1-\pi_{i}(y)\right\}^{\left(1-x_{i}\right)}, \\
h(y) & =h\left(y_{1}\right) \times \ldots \times h\left(y_{q}\right) .
\end{aligned}
$$

The parameters $\alpha_{\mathrm{i} 0}$ and $\alpha_{\mathrm{i} 1}, \ldots, \alpha_{\mathrm{iq}}$, included in $\pi_{\mathrm{i}}(\mathrm{y})$ can be estimated by maximum likelihood. An EM algorithm is employed to estimate the model with unobserved variables, using the TWOMISS program. Estimating the parameters allows us to give a response to the objective set previously of assigning the latent variable values to each individual or household as a function of the presence or lack of the observed conditions. All the information about latent variables is contained in the posterior distribution of such variables given a set of observed responses $\left(h\left(\mathrm{y} \mid \mathrm{x}_{1}, \ldots, \mathrm{x}_{\mathrm{p}}\right)\right)$, which we will call the response pattern $\left[\mathrm{x}=\left(\mathrm{x}_{1}, \ldots, \mathrm{x}_{\mathrm{p}}\right)\right]$. Using the logit link function shows that the posterior distribution depends on the observed variables through $q$ components. These components, called 'sufficient statistics', are given by:

$$
\mathrm{X}_{\mathrm{j}}=\sum_{i=1}^{q} \alpha_{i j} x_{i}, \quad j=1, \ldots, q, \text { with } q<p
$$

The components, which are a weighted sum of the observed responses using as weights the discrimination coefficients $\left(\alpha_{i j}\right)$, are used to score the individuals on the latent dimensions. The mean of that distribution, $E\left(\mathrm{y}_{\mathrm{j}} \mid \mathrm{x}_{1}, \ldots\right.$, $\left.\mathrm{x}_{\mathrm{p}}\right), \quad j=1, \ldots, q$, can also be used to scale individuals.

In order to validate the model, there are various goodness-of-fit measures. The most common involve computing a Pearson $\chi^{2}$ or the LR. Both statistics compare the observed frequency of each response pattern with the expected frequency:

$$
\chi^{2}=\sum_{r}^{2^{p}} \frac{(O(r)-E(r))^{2}}{E(r)}
$$




$$
\mathrm{LR}=2 \sum_{r=1}^{2^{p}} O(r) \ln \frac{O(r)}{E(r)}
$$

where $r$ represents a response pattern, and $\mathrm{O}(r)$ and $\mathrm{E}(r)$ represent, respectively, the observed and expected frequencies. Both statistics are distributed under the null as a $\chi^{2}$, with degrees of freedom equal to the number of different response patterns minus one minus the number of independent parameters.

Another option could be to use the relative change in the likelihood ratio statistic when we move from the independence model to the latent variable model in which the discriminating parameters are equal to zero $\left(\alpha_{i 1}=\ldots=\alpha_{i q}=0\right)$. This comparison offers information on the amount of association among the $x$ variables explained by the latent variables, $\mathrm{T}=\frac{G_{0}^{2}-G_{1}^{2}}{G_{0}^{2}}$, where $\mathrm{G}_{0}^{2}$ is the likelihood ratio test of the independence model. A final alternative, which we will also use in our subsequent estimation, is to compute the Pearson's $\chi^{2}$ statistic for pairs and triplets of responses. These values are equivalent to the residuals and offer us information on how well the model predicts the two and three way margins.

\section{DATA, VARIABLES AND RESULTS}

\subsection{Data and variables}

The interest in the influence of housing characteristics on health implies that the choice of a database is conditioned by the available information on both variables. The ECHP contains valuable information on housing facilities and specific housing problems. In addition, it includes enough details on other variables such as economic, employment and living conditions of the household. The data used come from waves for 1995, 1996, 1997 and 1998. As usual in this kind of studies, the unit of analysis is the individual, although the family context is sometimes relevant.

The dependent variable is the health status. It is defined in dichotomous terms: "being unhealthy" or "being healthy". It takes on the value of 1 whenever individuals state that they are in "very bad", "bad" or "fair" health and the value of 0 when they state they are in "good" or "very good" health. The explanatory 
variables are dictated both by the economic model for the production of health and the available information in the ECHP.

Housing conditions are defined by a set of dummies that take the value of 1 when an individual is deprived on some specific housing condition and 0 otherwise (see the Appendix for details). More specifically, the variables representing a lack of separate kitchen, bath, indoor flushing toilet, hot running water, central heating, garden and natural light indicate if the dwelling has this kind of facilities. After conducting a detailed study on the relationship between a lack of central heating, income and weather conditions for different Spanish regions, we consider that the lack of central heating in southern Spain (Andalucia, Murcia, Ceuta and Melilla) and the Canary Islands does not necessarily mean being in a state of deprivation. Another group of variables, which includes the presence of a leaky roof, damp and rot in floors and window frames, indicates if the dwelling is suffering from some kind of structural problem. The noise, pollution and vandalism variables represent the presence of environmental problems or crime and vandalism in the dwelling's surrounding area. Lastly, the overcrowding variable indicates whether or not the dwelling has space problems. Overcrowding is defined as a dwelling having a number of rooms less than the number of adults in the household. Establishing the space a person needs to live is necessarily a subjective matter. This is why alternative indicators have been used to take into account household composition. Sensitivity analyses do not show important effects on the estimates.

We have also considered suitable to include a subjective variable representing satisfaction with the dwelling's conditions. It aims to complement the information on housing deprivation by incorporating a measure of what could be called an individual's "psychological welfare". This variable varies in a scale ranging from "not satisfied at all" to "fully satisfied".

Other explanatory variables that have an influence on the stock of health are included, such as variables that explain individuals' economic, employment and social situations. Educational attainment is included as one of the determining factors for gross investment. It includes three dummies that reflect the different categories that refer to education. As a variable representing the stock of pre-existing health is included a dummy that provides information on the existence of chronic diseases. A set of dummies reflecting the different age and sex categories of individuals (see Appendix) is used as determining factors for the depreciation rate of the stock of health. 
Other explanatory variables could have an influence on the productivity of health investment and, hence, on the stock of health. The variable representing equivalent income gathers information on a household's total net real income per equivalent adult (the modified OECD equivalence scale recommended by EUROSTAT is used, which takes a single-person household as a reference and gives a weighting of 0.5 to the rest of the household's adults and 0.3 to children). In order to reflect different profiles at different income levels, we use a disaggregation by income deciles.

The social behaviour of individuals is represented by variables that reflect their level of social integration based on a set of five dummies (see again the Appendix). A set of dummies that gather information of the type of employment contract and the main source of income is included as an indicator of the employment situation. Dummies on the marital status of individuals are also added. Lastly, we include annual dummies in an attempt to control common time shocks.

\subsection{Empirical results}

\subsubsection{Results with different housing conditions}

The first empirical exercise we conduct consists of verifying to what extent it is necessary to introduce unobservable heterogeneity in the binary choice model. The results obtained from the likelihood ratio (LR) test show the need to estimate the model using individual effects. Although we focus our attention on these models, we present in Table A.1 of the Appendix the results of the logistic model without individual effects.

The results of the model with individual effects and disaggregated housing conditions (Model 1) are reported in the first column of Table 1. Of the whole set of variables representing individuals effects, we only report significant variables. The value of the Wald test confirms their explanatory power (Wald $(23)=1978.6083)$. We can observe too that most of the explanatory variables contribute significantly to explaining health status considered as a dichotomic variable. Results also confirm that the changes in the probability of being unhealthy in the face of marginal changes in the explanatory variables evolve as expected.

Concerning housing conditions, the results corroborate the expected negative effect on health of lacking some of these conditions. Once individuals 
effects are controlled, individuals who live in a dwelling that lacks hot running water or central heating have respectively a 24 and 5 percent higher probability of being unhealthy than individuals whose dwellings do not lack these conditions. Likewise, individuals belonging to households whose dwellings suffer from structural problems like a leaky roof, damp or rot in floor or window frames have a greater chance of being unhealthy than the rest of individuals. The overcrowding variable shows that living in an overcrowded dwelling increases the probability of being unhealthy by almost 11 percent. In general, these probabilities are slightly lower than the ones estimated without controlling heterogeneity. As regards to the satisfaction expressed by individuals with their housing conditions, there is also an inverse relationship between being satisfied with the dwelling and being unhealthy.

The results for the variables representing dwelling's facilities coincide with the findings obtained by studies carried out for other countries, showing a negative effect on health. In almost all cases, these variables make a significant contribution to explain the health status. These results therefore confirm the negative implications that the various symptoms of housing deprivation could have on health, an essential dimension of individual well-being.

However, there are other that affect health status. The stock of preexisting health is a very important factor. Hence, individuals who suffer from chronic illnesses have a greater probability of being unhealthy at a specific time than the rest. In quantitative terms, this factor has the greatest impact, which to some extent reflects state dependence while at the other picks up unobserved heterogeneity. Income also contributes significantly to explaining the health status [41]. Individuals with incomes in the upper deciles of the distribution particularly the last decile - have a lower probability of being unhealthy than individuals located in the lowest decile. Marital status also has a significant effect. In particular, being separated is the status with the greatest probability of being unhealthy.

Other factors that appear to have a positive influence on health are educational attainment and social relationships. Individuals whose highest level of education is secondary education are 15 percent less likely to be unhealthy than those with only primary school. Concerning social relationships, the results show that those individuals who are less socially integrated - those who meet people less often - have a greater likelihood of being unhealthy than those who meet people most days. 
Table 1. Binary logistic model with individual effects

\begin{tabular}{|c|c|c|c|c|}
\hline \multirow{2}{*}{ Health } & \multicolumn{2}{|c|}{ Model 1} & \multicolumn{2}{|c|}{ Model 2} \\
\hline & Odds Ratio & Std. Err. & Odds Ratio & Std. Err. \\
\hline \multicolumn{5}{|l|}{ Housing conditions } \\
\hline Have separate kitchen & 0.905 & 0.104 & & \\
\hline Have separate bath & 0.919 & 0.130 & & \\
\hline Have indoor flushing toilet & 0.847 & 0.138 & & \\
\hline Hot running water & 1.245 & 0.114 & & \\
\hline Heating & 1.047 & 0.029 & & \\
\hline Place to sit outside & 1.066 & 0.029 & & \\
\hline Noise problems & 0.999 & 0.028 & & \\
\hline Too dark & 1.077 & 0.035 & & \\
\hline Leaky roof & 1.064 & 0.046 & & \\
\hline Damp & 1.192 & 0.040 & & \\
\hline Rot in window frames or floor & 1.150 & 0.059 & & \\
\hline Pollution & 1.053 & 0.038 & & \\
\hline Vandalism & 1.182 & 0.036 & & \\
\hline Overcrowding & 1.104 & 0.041 & & \\
\hline Housing deprivation & & & 1.066 & 0.031 \\
\hline \multicolumn{5}{|l|}{ Marital Status } \\
\hline Separated & 1.327 & 0.145 & 1.335 & 0.145 \\
\hline Divorced & 1.049 & 0.160 & 1.063 & 0.161 \\
\hline Widowed & 1.187 & 0.157 & 1.163 & 0.153 \\
\hline Married & 0.941 & 0.153 & 0.909 & 0.147 \\
\hline \multicolumn{5}{|l|}{ Main source of income } \\
\hline Self-employment & 1.010 & 0.063 & 1.002 & 0.062 \\
\hline Pensions & 1.388 & 0.086 & 1.383 & 0.086 \\
\hline Unemployment benefits & 1.096 & 0.080 & 1.095 & 0.080 \\
\hline Other social benefits & 1.431 & 0.105 & 1.442 & 0.105 \\
\hline Private income & 1.069 & 0.083 & 1.067 & 0.082 \\
\hline Person has no income & 0.972 & 0.069 & 0.970 & 0.069 \\
\hline \multicolumn{5}{|l|}{ Education } \\
\hline 2nd stage (isced 3) & 0.847 & 0.064 & 0.855 & 0.064 \\
\hline 3rd level (isced 5-7) & 1.169 & 0.163 & 1.179 & 0.164 \\
\hline \multicolumn{5}{|l|}{ Social Relationship } \\
\hline Once/twice a week & 1.191 & 0.038 & 1.202 & 0.039 \\
\hline Once/twice a month & 1.232 & 0.071 & 1.237 & 0.071 \\
\hline Less often & 1.382 & 0.132 & 1.383 & 0.131 \\
\hline Never & 1.182 & 0.271 & 1.177 & 0.269 \\
\hline \multicolumn{5}{|l|}{ Age } \\
\hline$<25$ years & 0.668 & 0.122 & 0.665 & 0.121 \\
\hline $25-65$ years & 0.989 & 0.094 & 0.985 & 0.094 \\
\hline Chronic condition & 3.114 & 0.124 & 3.126 & 0.125 \\
\hline Sex & 0.809 & 0.023 & 0.812 & 0.023 \\
\hline$d t 95$ & 1.041 & 0.036 & 1.075 & 0.037 \\
\hline$d t 96$ & 0.933 & 0.032 & 0.958 & 0.033 \\
\hline$d t 97$ & 0.965 & 0.033 & 0.986 & 0.034 \\
\hline
\end{tabular}


Table 1 (cont.)

\begin{tabular}{|c|c|c|c|c|}
\hline \multicolumn{5}{|l|}{ Income } \\
\hline Decile 2 & 1.045 & 0.054 & 1.043 & 0.054 \\
\hline Decile 3 & 0.968 & 0.051 & 0.975 & 0.051 \\
\hline Decile 4 & 0.965 & 0.051 & 0.971 & 0.051 \\
\hline Decile 5 & 0.998 & 0.053 & 1.006 & 0.053 \\
\hline Decile 6 & 0.964 & 0.051 & 0.971 & 0.051 \\
\hline Decile 7 & 0.898 & 0.049 & 0.911 & 0.049 \\
\hline Decile 8 & 0.935 & 0.052 & 0.947 & 0.052 \\
\hline Decile 9 & 0.902 & 0.051 & 0.916 & 0.052 \\
\hline Decile 10 & 0.846 & 0.051 & 0.849 & 0.051 \\
\hline Satisfaction with housing & 0.926 & 0.013 & 0.916 & 0.013 \\
\hline \multicolumn{5}{|c|}{ Type of employment contract } \\
\hline Fixed/short-term contract & 0.680 & 0.077 & 0.679 & 0.077 \\
\hline Other arrangement & 0.793 & 0.141 & 0.786 & 0.140 \\
\hline Permanent employment & 0.828 & 0.090 & 0.828 & 0.090 \\
\hline Not working & 0.849 & 0.092 & 0.845 & 0.091 \\
\hline $\bar{z}_{m s t a t u s}$ & 1.106 & 0.046 & 1.116 & 0.046 \\
\hline $\bar{z}_{\text {sourceincome }}$ & 1.043 & 0.015 & 1.045 & 0.015 \\
\hline $\bar{z}_{\text {education }}$ & 0.660 & 0.048 & 0.661 & 0.048 \\
\hline $\bar{z}_{\text {relationship }}$ & 1.178 & 0.039 & 1.191 & 0.039 \\
\hline $\bar{z}_{\text {satisfactionwithhou } \sin g}$ & 0.913 & 0.018 & 0.918 & 0.019 \\
\hline $\bar{z}_{\text {age }}$ & 0.472 & 0.045 & 0.481 & 0.046 \\
\hline $\bar{z}_{\text {chronic }}$ & 9.382 & 0.508 & 9.310 & 0.503 \\
\hline $\bar{z}_{\text {hou } \sin \text { gdeprivation }}$ & & & 1.180 & 0.044 \\
\hline $\begin{array}{l}\text { Number of observations } \\
\text { Log Likelihood }\end{array}$ & \multicolumn{2}{|c|}{57960} & \multicolumn{2}{|c|}{58192} \\
\hline Chi2 & \multicolumn{2}{|c|}{$27383.89(58)$} & \multicolumn{2}{|c|}{$27458.69(46)$} \\
\hline Prob $>$ Chi2 & \multicolumn{2}{|c|}{0.000} & \multicolumn{2}{|c|}{0.000} \\
\hline LR test & \multicolumn{2}{|c|}{$1955.70(8)$} & \multicolumn{2}{|c|}{$2008.79(8)$} \\
\hline Prob>Chi2 (LR) & \multicolumn{2}{|c|}{0.000} & \multicolumn{2}{|c|}{0.000} \\
\hline
\end{tabular}

\section{Notes.}

1.- Baseline: not suffering housing deprivation, never married, earnings as the main source of income, less than $2^{\text {nd }}$ stage as highest level of education attained, first decile of equivalent income, not at all satisfied with housing, meet people most days, not chronic condition, casual work, woman, more than 65 years old.

2.- Degrees of freedom are in parenthesis after the test figures.

The last set of results deals with the relationship between the employment situation and the health status. Pensioners or individuals perceiving other social benefits show a greater chance of being in bad health than those who are wageearning. As in the case of the pre-existing stock of health, the effect of this variable diminishes considerably when individual effects are taken into consideration, thus pointing towards potential correlation among them. One explanation could be that most of these individuals receive disability or sickness benefits. Lastly, it can be observed that the fact of having a permanent or even a fixed/short-term employment contract, as opposed to not having one, increases the probability of being healthy. 


\subsubsection{Results with the latent variable of housing deprivation}

In order to assess the impact of different housing characteristics on health, it is necessary to demonstrate that each of the components or indicators making up the housing deprivation index serves as a proxy for the health status, both individually and as a group. The previous exercise has allowed us to make a preliminary approximation to the relationship between housing and health based on the different housing characteristics. The next step consists of summing up these dimensions in a single variable representing housing deprivation to confirm or refute the previous results. The interest of this second exercise is also due to the fact that the variables representing housing may be endogenous in a model that attempts to explain health status. The latent variable of housing deprivation can also be interpreted as an instrument for them.

The latent variable can be constructed from the housing variables which show a negative impact on health in the previous regression model. These variables are the same that turned out to be determining factors for social deprivation in another study that analyses the basic conditions needed to define housing deprivation in accordance with the criteria commonly used in the poverty literature. The indicators that make up the latent variable are hot running water, central heating, leaky roof, damp, rot in floor or window frames, and overcrowding.

The results of the latent trait model for each of the sub-periods show that the vector of observed variables $\left[\mathrm{x}=\left(\mathrm{x}_{1}, \ldots, \mathrm{x}_{\mathrm{p}}\right)\right]$ consists of hot running water, central heating, leaky roof, rot in floor or window frames and overcrowding variables, can be explained by a small number of latent variables. In this case, a single latent variable allows us to identify the variable underlying housing deprivation, and confirm the assumed a priori structure. The estimated parameters, their standard errors as well as goodness-of-fit measures are reported in Table 2. In general, the Pearson $\chi^{2}$ statistic and the LR test indicate that the fit is limited, as it is usual in this kind of models. Since there are many response patterns with expected frequencies less than five and given that the statistical program (TWOMISS) merges the response patterns, a degree of freedom is lost each time this process is made. The same cannot be said about the t-statistic, which indicates that the latent variable model can explain between 85 and 90 percent of the association among the $x$ variables. Another alternative consists of calculating the Pearson $\chi^{2}$ for combinations of two or three responses. The residuals offer information about the predictions the model makes on the response patterns composed of two or three elements (see Table A.2 in the Appendix). 
The last column in Table 2 shows the probabilities of a median individual responding positively to each of the six indicators. The indicators corresponding to the hot running water and rot in floor or window frames variables are the least likely to receive positive responses. The estimates of the discrimination parameters $\alpha_{i j}$ representing the weight of each of the observed variables are shown in the fourth column. The values of these parameters show that the central heating and overcrowding indicators have less weight than the other observed variables. At the same time, they are the ones that have the greatest probability of receiving a positive response. Additionally, the values corresponding to the hot running water and rot indicators show that they have greater weight than the previous ones, as they have a lower probability of receiving a positive response. To a certain extent, we can thus say that the latent variable constructed takes into account the housing conditions that only a very small percentage of the population lacks and assigns them greater weights.

We now re-estimate the logistic model with individual effects incorporating as a new regressor the latent variable representing housing deprivation. This procedure is aimed to check the robutness of the results reached by the specification including disaggregated housing characteristics as well as to control the possible endogeneity of these variables. As before, the values of the LR test provide clear evidence for the presence of unobserved heterogeneity, thus pointing towards the necessity of estimating the model with individual effects (Table 1). The results presented under the heading Model 2 confirm the findings of the previous specification. Most of the variables make a significant contribution to explain health status. The probability changes evolve as expected in the face of marginal changes in the explanatory variables. Moreover, the goodness-of-fit measures continue to show an adequate fit. 
Table 2. Maximum Likelihood Estimates of Item Parameters

\begin{tabular}{|c|c|c|c|c|c|c|}
\hline Items (year 1995) & $\alpha_{0 \mathrm{i}}$ & Standard error & $\alpha_{1 i}$ & Standard error & Standardised & $\alpha_{1 i} \quad P(X=1 / Z=0)$ \\
\hline Hot running water & -3.952 & 0.122 & 1.255 & 0.101 & 0.782 & 0.019 \\
\hline Heating & -0.084 & 0.026 & 0.477 & 0.041 & 0.431 & 0.479 \\
\hline Leaky roof & -4.027 & 0.191 & 2.585 & 0.171 & 0.933 & 0.018 \\
\hline Damp & -2.879 & 0.161 & 2.794 & 0.199 & 0.942 & 0.053 \\
\hline Rot in window/frames/floor & -4.056 & 0.165 & 2.231 & 0.138 & 0.913 & 0.017 \\
\hline Overcrowding & -2.679 & 0.053 & 0.274 & 0.068 & 0.264 & 0.064 \\
\hline$\%$ explained & & & & 88.31 & & \\
\hline LR test & & & & 88.89 & & \\
\hline$\chi^{2}(29)$ for observed response patt. & & & & 46.85 & & \\
\hline$\underline{\chi^{2}(29) \text { for all response patterns }}$ & & & & 68.25 & & \\
\hline Items (year 1996) & $\alpha_{0 \mathrm{i}}$ & Standard error & $\alpha_{1 i}$ & Standard error & Standardised & $\alpha_{1 \mathrm{i}} \quad \mathrm{P}(\mathrm{X}=1 / \mathrm{Z}=0)$ \\
\hline Hot running water & -4.377 & 0.154 & 1.432 & 0.116 & 0.82 & 0.012 \\
\hline Heating & -0.246 & 0.027 & 0.503 & 0.041 & 0.449 & 0.439 \\
\hline Leaky roof & -3.823 & 0.182 & 2.608 & 0.171 & 0.934 & 0.021 \\
\hline Damp & -3.352 & 0.257 & 3.645 & 0.322 & 0.964 & 0.034 \\
\hline Rot in window/frames/floor & -4.014 & 0.151 & 1.957 & 0.122 & 0.891 & 0.018 \\
\hline Overcrowding & -2.59 & 0.051 & 0.252 & 0.066 & 0.244 & 0.07 \\
\hline$\%$ explained & & & & 89.42 & & \\
\hline LR test & & & & 98.59 & & \\
\hline$\chi^{2}$ (26) for observed response patt. & & & & 61.57 & & \\
\hline$\chi^{2}(26)$ for all response patterns & & & & 79.88 & & \\
\hline Items (year 1997) & $\alpha_{0 \mathrm{i}}$ & Standard error & $\alpha_{1 \mathrm{i}}$ & Standard error & Standardised & $\alpha_{1 i} \quad P(X=1 / Z=0)$ \\
\hline Hot running water & -4.512 & 0.164 & 1.483 & 0.121 & 0.829 & 0.011 \\
\hline Heating & -0.382 & 0.028 & 0.431 & 0.041 & 0.396 & 0.406 \\
\hline Leaky roof & -3.738 & 0.185 & 2.615 & 0.175 & 0.934 & 0.023 \\
\hline Damp & -3.07 & 0.213 & 3.332 & 0.273 & 0.958 & 0.044 \\
\hline Rot in window/frames/floor & -4.5 & 0.205 & 2.393 & 0.161 & 0.923 & 0.011 \\
\hline Overcrowding & -2.547 & 0.054 & 0.333 & 0.069 & 0.316 & 0.073 \\
\hline$\%$ explained & & & & 84.86 & & \\
\hline LR test & & & & 154.56 & & \\
\hline$\chi^{2}$ (26) for observed response patt. & & & & 104.41 & & \\
\hline$\underline{\chi^{2}(26) \text { for all response patterns }}$ & & & & 133.50 & & \\
\hline Items (year 1997) & $\alpha_{0 \mathrm{i}}$ & Standard error & $\alpha_{1 \mathrm{i}}$ & Standard error & Standardised & $\alpha_{1 \mathrm{i}} \quad \mathrm{P}(\mathrm{X}=1 / \mathrm{Z}=0)$ \\
\hline Hot running water & -4.997 & 0.209 & 1.612 & 0.142 & 0.85 & 0.007 \\
\hline Heating & -0.396 & 0.029 & 0.406 & 0.044 & 0.376 & 0.402 \\
\hline Leaky roof & -4.521 & 0.284 & 2.86 & 0.246 & 0.944 & 0.011 \\
\hline Damp & -3.531 & 0.352 & 3.431 & 0.415 & 0.96 & 0.028 \\
\hline Rot in window/frames/floor & -4.365 & 0.181 & 2.037 & 0.139 & 0.898 & 0.013 \\
\hline Overcrowding & -2.639 & 0.056 & 0.205 & 0.076 & 0.201 & 0.067 \\
\hline$\%$ explained & & & & 90.40 & & \\
\hline LR test & & & & 89.12 & & \\
\hline$\chi^{2}$ (26) for observed response patt. & & & & 53.69 & & \\
\hline$\chi^{2}(26)$ for all response patterns & & & & 71.52 & & \\
\hline
\end{tabular}

Once the existence of specific individual effects is controlled, we again find evidence of negative influence of housing deprivation on the health status. More precisely, individuals living in houses having structural problems, lacking certain facilities or suffering from overcrowding have a greater probability then 
the rest of the population of stating they suffer from bad health. Moving up to the next score of the housing deprivation scale increases the probability of bad health by 7 percent. The relationship that exists between suffering housing deprivation, both individually and as a group, and the health status is therefore confirmed even when unobserved heterogeneity is controlled for.

We confirm previous results as regards most of the control variables. The value of the Wald test obtained for the set of variables reflecting individual effects (Wald $(10)=1978.4281$ ) confirms their explanatory capacity. The presence of chronic illnesses, diminish the probability of being in good health although this effect is attenuated when heterogeneity is controlled. Individuals with income levels situated in the upper deciles of the income distribution have a lower probability of suffering from bad health than those whose income levels lie in the lowest income decile. The positive influence exerted on health by factors like educational attainment, personal satisfaction with housing conditions, marital status and the level of social integration are confirmed again. Lastly, the results obtained for the influence exerted on an individual's health by the employment situation are also similar to those of the previous model. More specifically, the fact of not having a contract or having a pension or other social benefits as the main source of income increases the chances of being in fair, bad or very bad health. As before, we observe that the quantitative impact of social benefits diminishes considerably when individual effects are taken into consideration. This is why this factor is also considered as a fixed component representing the stock of pre-existing health.

\section{CONCLUSIONS}

The aim of this study has been to show the influence of housing deprivation on health status, as well as to assess the extent to which the existence of unobserved individual characteristics can condition this relationship. More precisely, we have tested the hypothesis that living in a deficient dwelling determines health status, once other observed and unobserved factors have ben controlled. Our interest in obtaining aswers to these questions is the important implications they have in the design of social policies. The reduced form health production, estimated as a discrete choice model with individual effects, has confirmed the negative relationship between housing deprivation and health. We test the robustness of the results using both a set of housing characteristics and an index of housing deprivation. Our results also confirm the importance of controlling both the observed as well as the unobserved heterogeneity among individuals. We must emphasize the importance that living in a dwelling that lacks hot running water or central 
heating; has structural problems like a leaky roof, damp or rot in the floor or window frames; or suffers from problems of overcrowding has on individuals' health status.

Nonetheless, housing conditions are not the only relevant detereminants of health status. The inclusion of other variables has allowed us to verify the influence exerted by other economic and social variables. The presence of chronic illnesses, age, the fact of being a woman, belonging to the lower deciles of the income distribution, being unemployed, or having a pension or other social security benefits as the main source of income all increase the probability of individuals stating they are in fair, bad or very bad health. On the other hand, the higher the educational attainment and the social integration the higher the probability of being healthy.

The evidence that housing conditions have a clear influence on health (confirmed when the existence of a great degree of heterogeneity is taken into account) allow us to underline some possible implications on health care policies, with all due caution. The most general of these is that initiatives geared towards promoting better health among the population should not be totally circumscribed to Departments of Health. On the contrary, it is necessary the implementation of broader initiatives that would take into account housing deprivation as one of important determinant of health. 


\section{REFERENCES}

Albanese, M.T. and Knott, M., TWOMISS: A Computer Program for Fitting a One -or Two- Factor Logit-Probit Latent Variable Model to Binary Data When Observations May be Missing. Technical Report, Statistics Department, London School of Economics and Political Science, 1990.

Auster, R., Leveson, I. and Sarachek, D., The Production of Health, an Exploratory Study. Journal of Human Resources 1969; 4: 411-36.

Baltagi, B.H., Econometric Analysis of Panel Data. John Wiley \& Sons, 2001.

Bartholomew, D. J. and Knott M., Latent Variable Models \& Factor Analysis. Griffin, 1999.

Bartholomew, D.J. and Tzamourani, P., The Goodness-of-Fit of Latent Trait Models in Attitude Measurement. Sociological Methods and Research 1999; 27: 525-46.

Becker, G.S. A Theory of the Allocation of Time. Economic Journal 1965; 75: 493-517.

Bock, R.D. and Aitkin, M., Marginal Maximum Likelihood Estimation of Item Parameters: Application of an EM Algorithm. Applied Psychological Measurement 1981; 37: 29-51.

Bolin, K., Jacobsson, L. and Lindgren, B., Employer Investments in Employee Health. Implications for the Family as Health Producer. Journal of Health Economics 2002; 21: 563-83.

Bolin, K., Jacobsson, L. and Lindgren, B., The Family as Health Producer-The Case when Family Members are Nash-Bargainers. Journal of Health Economics 2001; 20: 349-62.

Bolin, K., Jacobsson, L. and Lindgren, B., The Family as Health Producer When Spouses Act Strategically. Journal of Health Economics 2002; 21: 475-95.

Borg, V. and Kristensen, T., Social Class and Self-Rated Health: Can the Gradient be Explained by Differences in Lifestyle or Work Environment? Social Science and Medicine 2000; 51: 1019-30.

British Medical Association Board of Science and Education. Housing and Health: Building for the Future. United Kingdom: British Medical Association, 2003.

Burstrom, B. and Fredlund, P., Self-Rated Health: Is it a Good Predictor of Subsequent Mortality among Adults in Lower as well as in Higher Social Classes? Epidemiology and Community Health 2001; 55: 836-40. 
Chiappero, E. A., Multidimensional Assessment of Well-being Based on Sen's Functioning Approach. Rivista Internazionale di Scienze Sociali 2000; 2: 207-39.

Contoyannis, P. and Jones, A.M., Socioeconomic Status, Health and Lifestyle. Journal of health economics. Forthcoming.

Dale, A., Williams, M. and Dodgeon, B., Housing Deprivation and Social Change : A report based on the analysis of individual level census data for 1971, 1981 and 1991 drawn from the Longitudinal study and the Samples of anonymised records. Office For National Statistics, Series LS No. 8. London: HMSO, 1996.

Department of Health. Green Paper: Our Healthier Nation. London: The Stationery Office, 1998.

Department of Health. White Paper: Our Healthier Nation. London: The Stationery Office, 1999.

Dunn, J.R., Housing and Health Inequalities: Review and Prospects for Research. Housing Studies 2000; 15: 341-66.

Grossman, M., On the Concept of Health Capital and the Demand for Health. Journal of Political Economy 1972; 80: 223-55.

Grossman, M., The Demand for Health: A Theoretical and Empirical Investigation. Occasional Paper National Bureau of Economic Research 1972; 119.

Grossman, M., The Human Capital Model of the Demand of Health. NBER Working Paper 1999; 7078.

Hsiao, C., Benefits and Limitations of Panel Data. Econometric Reviews 1985; 4: 121-74.

Ineichein, B., Homes and Health. London: E \& FN Spon, 1993.

Jacobson, L., The Family as a Producer of Health - An Extended Grossman Model. Journal of Health Economics 2000; 19: 611-37.

Kemna, H., Working Conditions and the Relationship between Schooling and Health. Journal of Health Economics 1987; 6: 189-210.

Kenkel, D.S., Should you Eat Breakfast? Estimates from Health Production Functions. Health Economics 1995; 4: 15-29.

Kunst, A.E., Geurts, J. and Van Den Berg, J., International Variation in Socioeconomic Inequalities in Self-Reported Health. Journal of Epidemiology and Community Health 1995.

Lowry, S., Housing and Health London: BMJ, 1991. 
Manning, W., Newhouse, J.P. and Ware, J.E., The Status of Health in Demand Estimation; or, Beyond Excellent, Good, Fair, Poor. In: Fuchs, V. (ed), Economic Aspects of Health. Chicago: University of Chicago Press, 1981.

Marsh, A., Gordon, D., Heslop, P. and Pantazis, C., Housing Deprivation and Health: A Longitudinal Analysis. Housing Studies 2000; 15: 411-28.

Matyas, L. and Sevestre, P. (eds), The Econometrics of Panel Data. Kluwer Academic Publishers: The Netherlands, 1992.

Ministry of Social Development and Economic Security. Homelessness-Causes \& Effects: The Cost of Homelessness in British Columbia. British Columbia Ministry of Social Development and Economic Security and BC Housing Management Commission, Volume 3, 2001.

Moisio, P. A., Latent Class Application to the Measurement of Poverty. IRISS Working Paper Series 2001,8. CEPS/INSTEAD, Luxembourg.

Navarro, C., La privación en vivienda en España: Una aproximación a su extensión, dinámica y efectos sobre el bienestar a través de índices multidimensionales de privación. Doctoral Thesis, 2003. Mimeograph

Navarro, C., Privación en vivienda y estado de salud: una estimación para el caso español. In: Cabases J.M. et al. (eds): La organización territorial de la sanidad. Navarra: Universidad Pública de Navarra, Asociación de Economía de la Salud, 2002: 377-404.

Power, C. and Hertzman, C., Social and Biological Pathways Linking Early Life and Adult Disease. In: Marmot, M. and Wadsworth, M. (eds), Fetal and Early Childhood Environment: Long-Term Health Implications. British Medical Bulletin 1997; 53: 210-23.

Rosenzweig, M. and Schultz, T.P., Estimating a Household Production Function: Heterogeneity, the Demand for Health Inputs, and their Effects on Birth Weight. Journal of Political Economy 1983; 91: 723-46.

Smith, S.J., Housing and Health: A Review and Research Agenda. Discussion Paper, 27, Centre for Housing Research, Glasgow University, 1989.

Taubman, P. and Rosen, S., Healthiness, Education and Marital Status. In: Fuchs, V. (ed)., Economic Aspects of Health. Chicago: University of Chicago Press, 1981.

Van Doorslaer, E., et al. Income-Related Inequalities in Health: Some International Comparisons. Journal of Health Economics 1997; 16: 93112.

Wagstaff, A., Van Doorslaer E. and Paci, P., Equity in the Finance and Delivery of Health Care: Some Tentative Cross-Country Comparisons. Oxford Review of Economic Policy 1989; 5: 89-112. 
Appendix

Table A.1 Standard binary logistic model

\begin{tabular}{|c|c|c|c|c|}
\hline \multirow{2}{*}{ Health } & \multicolumn{2}{|c|}{ Model 1} & \multicolumn{2}{|c|}{ Model 2} \\
\hline & Odds Ratio & Std. Err. & Odds Ratio & Std. Err. \\
\hline \multicolumn{5}{|l|}{ Housing conditions } \\
\hline Have separate kitchen & 0.892 & 0.100 & & \\
\hline Have separate bath & 0.987 & 0.135 & & \\
\hline Have indoor flushing toilet & 0.800 & 0.127 & & \\
\hline Hot running water & 1.305 & 0.117 & & \\
\hline Heating & 1.063 & 0.028 & & \\
\hline Place to sit outside & 1.076 & 0.028 & & \\
\hline Noise problems & 0.987 & 0.027 & & \\
\hline Too dark & 1.088 & 0.034 & & \\
\hline Leaky roof & 1.093 & 0.046 & & \\
\hline Damp & 1.212 & 0.040 & & \\
\hline Rot in window frames or floor & 1.156 & 0.058 & & \\
\hline Pollution & 1.061 & 0.037 & & \\
\hline Vandalism & 1.207 & 0.036 & & \\
\hline Overcrowding & 1.116 & 0.041 & & \\
\hline Housing deprivation & & & 1.210 & 0.021 \\
\hline \multicolumn{5}{|l|}{ Marital Status } \\
\hline Separated & 1.621 & 0.153 & 1.638 & 0.154 \\
\hline Divorced & 1.397 & 0.179 & 1.427 & 0.182 \\
\hline Widowed & 1.723 & 0.098 & 1.722 & 0.098 \\
\hline Married & 1.455 & 0.053 & 1.438 & 0.052 \\
\hline \multicolumn{5}{|l|}{ Main source of income } \\
\hline Self-employment & 0.999 & 0.061 & 0.987 & 0.060 \\
\hline Pensions & 1.676 & 0.100 & 1.671 & 0.099 \\
\hline Unemployment benefits & 1.157 & 0.081 & 1.159 & 0.081 \\
\hline Other social benefits & 2.318 & 0.145 & 2.341 & 0.146 \\
\hline Private income & 1.274 & 0.081 & 1.272 & 0.080 \\
\hline Person has no income & 1.174 & 0.056 & 1.173 & 0.056 \\
\hline \multicolumn{5}{|l|}{ Education } \\
\hline 2nd stage (isced 3) & 0.534 & 0.020 & 0.535 & 0.020 \\
\hline 3rd level (isced 5-7) & 0.499 & 0.021 & 0.499 & 0.021 \\
\hline \multicolumn{5}{|l|}{ Social Relationship } \\
\hline Once/twice a week & 1.274 & 0.036 & 1.289 & 0.036 \\
\hline Once/twice a month & 1.455 & 0.071 & 1.475 & 0.071 \\
\hline Less often & 1.796 & 0.149 & 1.815 & 0.150 \\
\hline Never & 1.833 & 0.385 & 1.855 & 0.389 \\
\hline \multicolumn{5}{|l|}{ Age } \\
\hline$<25$ years & 0.133 & 0.009 & 0.137 & 0.009 \\
\hline $25-65$ years & 0.448 & 0.019 & 0.454 & 0.019 \\
\hline Chronic condition & 11.045 & 0.306 & 11.055 & 0.305 \\
\hline $\operatorname{Sex}$ & 0.800 & 0.022 & 0.801 & 0.022 \\
\hline$d t 95$ & 1.172 & 0.038 & 1.187 & 0.039 \\
\hline$d t 96$ & 1.004 & 0.033 & 1.010 & 0.033 \\
\hline$d t 97$ & 1.022 & 0.034 & 0.999 & 0.034 \\
\hline
\end{tabular}


Table A.1 (cont.)

\begin{tabular}{|c|c|c|c|c|}
\hline \multicolumn{5}{|l|}{ Income } \\
\hline Decile 2 & 1.092 & 0.055 & 1.086 & 0.054 \\
\hline Decile 3 & 1.006 & 0.051 & 1.008 & 0.051 \\
\hline Decile 4 & 1.000 & 0.051 & 0.996 & 0.051 \\
\hline Decile 5 & 1.032 & 0.053 & 1.027 & 0.053 \\
\hline Decile 6 & 1.010 & 0.052 & 1.002 & 0.051 \\
\hline Decile 7 & 0.911 & 0.048 & 0.909 & 0.048 \\
\hline Decile 8 & 0.965 & 0.052 & 0.959 & 0.051 \\
\hline Decile 9 & 0.922 & 0.051 & 0.915 & 0.050 \\
\hline Decile 10 & 0.855 & 0.050 & 0.837 & 0.049 \\
\hline Satisfaction with housing & 0.886 & 0.009 & 0.872 & 0.008 \\
\hline \multicolumn{5}{|l|}{ Type of employment contract } \\
\hline Fixed/short-term contract & 0.680 & 0.076 & 0.682 & 0.076 \\
\hline Other arrangement & 0.804 & 0.142 & 0.803 & 0.142 \\
\hline Permanent employment & 0.822 & 0.088 & 0.823 & 0.088 \\
\hline Not working & 0.930 & 0.099 & 0.933 & 0.100 \\
\hline Number of observations & \multicolumn{2}{|c|}{57960} & \multicolumn{2}{|c|}{58192} \\
\hline Log Likelihood & \multicolumn{2}{|c|}{-24119.765} & \multicolumn{2}{|c|}{-24259.154} \\
\hline Chi2 & \multicolumn{2}{|c|}{$(51)=25428.20$} & \multicolumn{2}{|c|}{$(38)=25449.89$} \\
\hline Prob $>$ Chi2 & \multicolumn{2}{|c|}{0.000} & \multicolumn{2}{|c|}{0.000} \\
\hline
\end{tabular}


Table A.2. Summary of Second and Third Order Observed and Expected Margins

\begin{tabular}{|c|c|c|c|c|c|c|}
\hline Year & Response & Observed & Expected & Observed-Expected & Max. $(\mathrm{O}-\mathrm{E})^{2} / \mathrm{E}$ & Items \\
\hline \multirow{5}{*}{1995} & $(1.1)$ & 88 & 67.5241 & 20.4759 & 6.2091 & (5.1) \\
\hline & $(1.0)$ & 167 & 181.1074 & -14.1074 & 1.0989 & $(5.2)$ \\
\hline & $(0.1)$ & 150 & 170.5435 & -20.5435 & 2.4746 & $(5.1)$ \\
\hline & $(0.0)$ & 5844 & 5823.3717 & 20.6283 & 0.0731 & (5.1) \\
\hline & $(1.1 .1)$ & 14 & 7.2054 & 6.7946 & 6.4073 & $(1.5 .6)$ \\
\hline \multirow{5}{*}{1996} & $(1.1)$ & 65 & 49.7372 & 15.2628 & 4.6837 & $(5.1)$ \\
\hline & $(1.0)$ & 125 & 157.6978 & -32.6978 & 6.7797 & $(5.2)$ \\
\hline & $(0.1)$ & 80 & 67.3970 & 12.6030 & 2.3567 & $(4.1)$ \\
\hline & $(0.0)$ & 3335 & 3301.6362 & 33.3638 & 0.3371 & $(5.2)$ \\
\hline & $(1.1 .1)$ & 47 & 34.0366 & 12.9634 & 4.9374 & $(1.2 .5)$ \\
\hline \multirow{5}{*}{1997} & $(1.1)$ & 105 & 87.4148 & 17.5852 & 3.5376 & $(2.1)$ \\
\hline & $(1.0)$ & 137 & 164.8155 & -27.8155 & 4.6943 & $(5.2)$ \\
\hline & $(0.1)$ & 55 & 73.3834 & -18.3834 & 4.6053 & $(2.1)$ \\
\hline & $(0.0)$ & 2813 & 2845.0000 & -32.7030 & 0.3758 & $(4.2)$ \\
\hline & $(1.1 .1)$ & 17 & 27.0595 & -10.0595 & 3.7397 & $(3.5 .6)$ \\
\hline \multirow{5}{*}{1998} & $(1.1)$ & 184 & 161.7401 & 22.2599 & 3.0636 & $(5.2)$ \\
\hline & $(1.0)$ & 111 & 133.0863 & -22.0863 & 3.6653 & $(5.2)$ \\
\hline & $(0.1)$ & 40 & 52.2466 & -12.2466 & 2.8706 & $(2.1)$ \\
\hline & $(0.0)$ & 3140 & 3118.2857 & 21.7143 & 0.1512 & $(5.2)$ \\
\hline & $(1.1 .1)$ & 3 & 5.6697 & -2.6697 & 1.2571 & (1.2.6) \\
\hline
\end{tabular}

Note: The sixth column of this table shows the highest residuals of each of the second and third order combinations. Hence, for instance, the second row shows that there are 167 individuals that responded positively to indicators 5 and 2 and the highest residual registered for this pattern of responses in 1.0989. Only values above 4 o 5 can indicate a bad fit for the model. Despite the fact that there are some residuals with a value above five, we can therefore conclude that the fit of the model with the unidimensional latent variable is satisfactory. 
Table A. 3. Variable definition and descriptives

\begin{tabular}{|c|c|c|c|c|c|}
\hline \multirow{2}{*}{ Variables } & \multirow{2}{*}{ Definition } & \multicolumn{4}{|c|}{$\mu$} \\
\hline & & 1995 & 1996 & 1997 & 1998 \\
\hline \multicolumn{6}{|l|}{ Dependent variable } \\
\hline Health & Unhealthy: (yes=1) $($ not $=0)$ & 0.34 & 0.33 & 0.32 & 0.32 \\
\hline $\begin{array}{l}\text { Health in general (original } \\
\text { variable) }\end{array}$ & $\begin{array}{l}\text { Health in general: very } \operatorname{good}(=1) \operatorname{good}(=2) \text { fair }(=3) \text { bad }(=4) \\
\text { and very bad(=5). }\end{array}$ & 2.29 & 2.26 & 2.26 & 2.28 \\
\hline \multicolumn{6}{|l|}{ Housing conditions } \\
\hline Have separate kitchen & deprived $($ yes $=1)($ not $=0)$ & 0.01 & 0.01 & 0.01 & 0.01 \\
\hline Have separate bath & deprived $($ yes $=1)($ not $=0)$ & 0.01 & 0.01 & 0.01 & 0.01 \\
\hline Have indoor flushing toilet & deprived $($ yes $=1)($ not $=0)$ & 0.01 & 0.01 & 0.01 & 0.00 \\
\hline Hot running water & deprived $($ yes $=1)($ not $=0)$ & 0.03 & 0.02 & 0.02 & 0.02 \\
\hline Heating & deprived $($ yes $=1)($ not $=0)$ & 0.46 & 0.43 & 0.39 & 0.40 \\
\hline Place to sit outside & deprived $($ yes $=1)($ not $=0)$ & 0.27 & 0.24 & 0.27 & 0.24 \\
\hline Noise problems & Noise problems $($ yes $=1)($ not $=0)$ & 0.18 & 0.21 & 0.17 & 0.15 \\
\hline Too dark & Not enough light $($ yes $=1)($ not $=0)$ & 0.10 & 0.12 & 0.11 & 0.09 \\
\hline Leaky roof & Leaky roof $($ yes $=1)($ not $=0)$ & 0.20 & 0.21 & 0.23 & 0.18 \\
\hline Damp & Damp $($ yes $=1)($ not $=0)$ & 0.08 & 0.07 & 0.06 & 0.05 \\
\hline \multicolumn{2}{|c|}{ Rot in window frames or floor Rot in window/frame/floor $($ yes $=1)($ not $=0)$} & 0.31 & 0.35 & 0.33 & 0.29 \\
\hline Pollution & Pollution problems $($ yes $=1)($ not $=0)$ & 0.19 & 0.14 & 0.13 & 0.13 \\
\hline Vandalism & Vandalism problems $(\mathrm{yes}=1)(\mathrm{not}=0)$ & 0.24 & 0.21 & 0.19 & 0.18 \\
\hline Overcrowding & Less rooms than number of adults (yes $=1)($ not $=0)$ & 0.14 & 0.15 & 0.17 & 0.15 \\
\hline Housing Deprivation & Index of housing deprivation & 0.01 & 0.02 & 0.02 & -0.01 \\
\hline Satisfaction with housing & $\begin{array}{l}\text { Level of satisfaction: scale 1-6. Not at all satisfied(=1). fully } \\
\text { satisfied }(=6) \text {. }\end{array}$ & 4.39 & 4.39 & 4.35 & 4.49 \\
\hline \multirow{4}{*}{ Marital Status } & separated $($ yes $=1)($ not $=0)$ & 0.01 & 0.01 & 0.01 & 0.01 \\
\hline & divorced $($ yes $=1)($ not $=0)$ & 0.01 & 0.01 & 0.01 & 0.01 \\
\hline & widowed (yes=1) $($ not $=0)$ & 0.08 & 0.08 & 0.08 & 0.08 \\
\hline & $\operatorname{married}(\mathrm{yes}=1)(\mathrm{not}=0)$ & 0.60 & 0.59 & 0.57 & 0.56 \\
\hline Sex & $\operatorname{male}(=1)$, female $(=0)$ & 0.48 & 0.48 & 0.49 & 0.48 \\
\hline \multirow{2}{*}{ Age } & $25-65$ years old $($ yes $=1)($ not $=0)$ & 0.64 & 0.64 & 0.63 & 0.63 \\
\hline & $16-25$ years old $($ yes $=1)($ not $=0)$ & 0.19 & 0.19 & 0.20 & 0.19 \\
\hline Chronic condition & Chronic condition: $($ yes $=1)($ not $=0)$ & 0.23 & 0.23 & 0.23 & 0.23 \\
\hline \multirow{4}{*}{ Type of employment contract } & Fixed/short-term contract $($ yes $=1)($ not $=0)$ & 0.09 & 0.08 & 0.08 & 0.08 \\
\hline & Other arrangement $($ yes $=1)(\mathrm{not}=0)$ & 0.01 & 0.01 & 0.01 & 0.01 \\
\hline & Permanent employment(yes $=1)($ not $=0)$ & 0.18 & 0.18 & 0.19 & 0.20 \\
\hline & Not working $($ yes $=1)($ not $=0)$ & 0.72 & 0.72 & 0.71 & 0.70 \\
\hline \multirow{2}{*}{ Education } & 2nd stage (isced 3$)($ yes $=1)($ not $=0)$ & 0.18 & 0.19 & 0.19 & 0.19 \\
\hline & $3 \mathrm{rd}$ level (isced 5-7)(yes $=1)($ not $=0)$ & 0.14 & 0.14 & 0.14 & 0.19 \\
\hline \multirow{4}{*}{ Social relationship } & Once/twice a week $($ yes $=1)($ not $=0)$ & 0.22 & 0.21 & 0.25 & 0.24 \\
\hline & Once/twice a month $($ yes $=1)($ not $=0)$ & 0.06 & 0.06 & 0.06 & 0.05 \\
\hline & Less often $($ yes $=1)($ not $=0)$ & 0.02 & 0.02 & 0.02 & 0.02 \\
\hline & Never $($ yes $=1)($ not $=0)$ & 0.00 & 0.00 & 0.01 & 0.00 \\
\hline \multirow{6}{*}{ Main source of income } & Self-employed $($ yes $=1)($ not $=0)$ & 0.06 & 0.06 & 0.06 & 0.07 \\
\hline & Pensions $($ yes $=1)($ not $=0)$ & 0.17 & 0.17 & 0.17 & 0.17 \\
\hline & Unemployment. benefits $($ yes $=1)($ not $=0)$ & 0.04 & 0.03 & 0.03 & 0.03 \\
\hline & Other social benefits $($ yes $=1)($ not $=0)$ & 0.07 & 0.07 & 0.07 & 0.06 \\
\hline & Private income $($ yes $=1)($ not $=0)$ & 0.06 & 0.05 & 0.07 & 0.09 \\
\hline & Person has no income $($ yes $=1)($ not $=0)$ & 0.27 & 0.30 & 0.28 & 0.26 \\
\hline
\end{tabular}

Notes:

1. Weighted data based on the variable representing cross-sectional weighting for each year.

2. Baseline: to be healthy, not suffering housing deprivation, not at all satisfied with housing, never married, woman, more than 65 years old, not chronic condition, casual work (type of employment contract), less than $2^{\text {nd }}$ stage as highest level of education attained, first decile of equivalent income, meet people most days and earnings as the main source of income. 


\section{RELACION DE DOCUMENTOS DE FEDEA}

\section{DOCUMENTOS DE TRABAJO}

2005-02: "Housing deprivation and health status: Evidence from Spain" Luis Ayala, José M. Labeaga y Carolina Navarro.

2005-01: “QQué determina el éxito en unas Oposiciones?”, Manuel F. Bagüés.

2004-29: "Demografía y empleo de los trabajadores próximos a la jubilación en Cataluña", J. Ignacio Conde-Ruiz y Emma García

2004-28: "The border effect in Spain", Salvador Gil-Pareja, Rafael Llorca-Vivero, José A. Martínez-Serrano y Josep Oliver-Alonso.

2004-27: "Economic Consequences of Widowhood in Europe: Cross-country and Gender Differences" Namkee Ahn.

2004-26: "Cross-skill Redistribution and the Tradeoff between Unemployment Benefits and Employment Protection", Tito Boeri, J. Ignacio Conde-Ruiz y Vincenzo Galasso.

2004-25: "La Antigüedad en el Empleo y los Efectos del Ciclo Económico en los Salarios. El Caso Argentino", Ana Carolina Ortega Masagué.

2004-24: "Economic Inequality in Spain: The European Union Household Panel Dataset", Santiago Budría y Javier Díaz-Giménez.

2004-23: "Linkages in international stock markets: Evidence from a classification procedure", Simon Sosvilla-Rivero y Pedro N. Rodríguez.

2004-22: "Structural Breaks in Volatility: Evidence from the OECD Real Exchange Rates", Amalia Morales-Zumaquero y Simon Sosvilla-Rivero.

2004-21: "Endogenous Growth, Capital Utilization and Depreciation", J. Aznar-Márquez y J. R. Ruiz-Tamarit.

2004-20: "La política de cohesión europea y la economía española. Evaluación y prospectiva", Simón Sosvilla-Rivero y José A. Herce.

2004-19: "Social interactions and the contemporaneous determinants of individuals' weight", Joan Costa-Font y Joan Gil.

2004-18: "Demographic change, immigration, and the labour market: A European perspective", Juan F. Jimeno.

2004-17: "The Effect of Immigration on the Employment Opportunities of Native-Born Workers: Some Evidence for Spain", Raquel Carrasco, Juan F. Jimeno y Ana Carolina Ortega.

2004-16: "Job Satisfaction in Europe”, Namkee Ahn y Juan Ramón García.

2004-15: "Non-Catastrophic Endogenous Growth and the Environmental Kuznets Curve", J. AznarMárquez y J. R. Ruiz-Tamarit.

2004-14: "Proyecciones del sistema educativo español ante el boom inmigratorio", Javier Alonso y Simón Sosvilla-Rivero.

2004-13: "Millian Efficiency with Endogenous Fertility", J. Ignacio Conde-Ruiz, Eduardo L. Giménez y Mikel Pérez-Nievas.

2004-12: "Inflation in open economies with complete markets", Marco Celentani, J. Ignacio Conde Ruiz y Klaus Desmet.

2004-11: "Well-being Consequences of Unemployment in Europe", Namkee Ahn, Juan Ramón García López y Juan F. Jimeno

2004-10: "Regímenes cambiarios de facto y de iure. Una aplicación al tipo de cambio yen/dólar", Francisco Ledesma-Rodríguez, Manuel Navarro-Ibáñez, Jorge Pérez-Rodríguez y Simón Sosvilla-Rivero.

\section{TEXTOS EXPRESS}

2004-02: “¿Cuán diferentes son las economías europea y americana?”, José A. Herce.

2004-01: "The Spanish economy through the recent slowdown. Current situation and issues for the immediate future", José A. Herce y Juan F. Jimeno. 